$$
\begin{aligned}
& \text { استخدام نقاط دلالة ضوئية في إيجاد أبعاد الجسم في الصور الرقمية } \\
& \text { سندس خليل إبراهيم } \\
& \text { كلية عوم الحاسبات والرياضيات } \\
& \text { جامعة الموصل }
\end{aligned}
$$

sunduskhaleel_2019@uomosul.edu.iq

$$
\text { تاريخ قبول البحث:2010/11/10 }
$$

تاريخ استلام البحث:2010/8/21

\title{
الملخص
}

نظرا للتطور الحاصل في مجال معالجة الصور الرقمية واستخداماتها في شتى المجالات، ولوجود الحاجة

في بعض التطبيقات منها الهندسية لقياس أبعاد الجسم عن بعد وفي مجال المرور لتحديد ارتفاع المركبات لعبورها تقاطعات الجسور والأنفاق ورصد المخالفات المرورية الخاصة ببروز الحمل عن جسم المركبة أكثر من الحد المسموح به. لذا فقد تم في هذا البحث اقتراح طريقة لإيجاد أبعاد الجسم باستخدام الصور الرقمية ذات الامتداد (jpg)، ولغرض القيام بذلك فقد ارتأينا تحوير جهاز الكاميرا الرقمية بإضافة أداة تتضمن مصدرين ضوئيين يبعثان الضوء على الجسم الذي سيصور وعن طريق النقاط الضوئية سيتم إيجاد مقياس الرسم والذي على أساسه سيتم

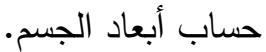

تم تتفيذ الطريقة المقترحة على عدة صور مختلفة تضم أجسام مختلفة، وقد أظهرت كفاءةً ودقة تصل 100\% في إيجاد أبعاد الجسم. ونفذت الخوارزمية بلغة Matlab R2010 ver. 7.0 باستخدام الحاسوب المحمول (Laptop) وبمواصفات: معالج Intel ${ }^{\mathrm{R}}$ Core $^{\mathrm{TM}}$ Solo CPU U3500, 1.4GHz وشاشة ذات دقة $.768 * 1366$

الكلمات المفتاحية: معالجة الصور، تمييز الكائن، الذرعات في الهندسة المدنية ، قياس الابعاد، تمييز الالوان، تمييز اللون الاخضر.

\section{Using index light points to determine object dimensions in the digital images}

\section{Sundus Khaleel Ebraheem}

College of Computer Sciences and Mathematics

University of Mosul

sunduskhaleel_2019@uomosul.edu.iq

Received on: 21/8/2010

Accepted on: 10/11/2010

\begin{abstract}
Due to the huge development in the digital image processing scope and its wide used in many applications, and exist the needing in some applications such as engineering, military to find remotely the object dimensions and area and in the traffic field to find the height of trucks before the tunnels and intersections bridges and
\end{abstract}


observation the traffic infringements that concerning the load part out of the vehicle body which may be more than the permissible limit.

Therefore, this paper suggest an approach to find the object dimensions by using digital images with an extension. The digital camera was modified by adding two lighting beams to apply point lights on the objet during image capturing. Then by using these two lighted points in the image the scale of the image was found which will be use to find object dimensions.

The proposed method applied by using many images with different objects. It was more efficient and accuracy $100 \%$ for determining dimensions of objects. It was applied by using Matlab R2010 ver. 7.0 language, laptop computer with $1.4 \mathrm{GHz}$ processor Intel $^{\mathrm{R}}$ Core $^{\mathrm{TM}}$ Solo CPU U3500, screen resolution $1366^{* 768 .}$

Keywords: Image Processing, Object Recognition, Civil Engineering Measuring, Dimension Measuring, Colors Recognition, Green color Recognition.

يشهد مجال معالجة الصور تقدما واسعا وكبيرا لما لهذا الحقل من أهمية في جميع مجالات الحياة. إذ

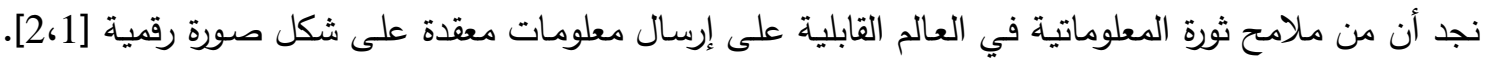
وبما أن الصورة تلعب دورا هاما في اكتساب البشر للمعلومات، لذا فإن الاهتمام بموضوع المعالجة الرقمية للصور ينبع من مجالين أساسيين: الأول في تحسين المعلومات المصورة لتسهيل تفسيرها وفهمها للبشر وتمهيدها لخطوات معالجة لاحقة. والثاني في

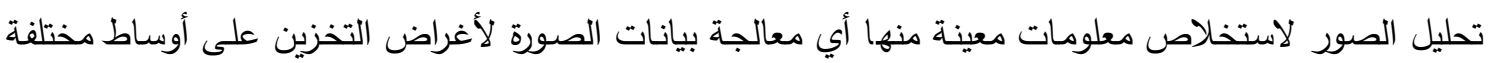

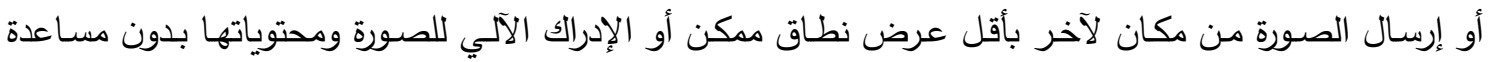
بشرية [4,3,2,1]

تعد معالجـة الصورة (image processing) من أحد فروع علم الحاسوب (المعلوماتية),الذي يهتت

بإجراء عمليات على الصور بهدف تحسنيها طبقاً لمعايير محددة أو استخلاص بعض المعلومات منها [5,1 وتعرف الصورة الرقمية على أنها مصفوفة ثنائية تتكون من عدد محدود من العناصـر لكل منها موقع وقيمـة

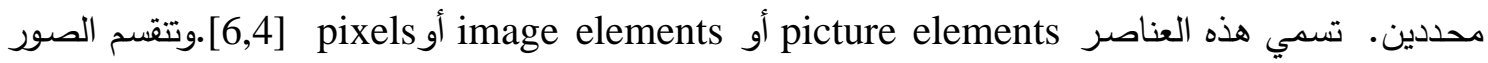
إلى الصورة ثنائية Binary Image والصورة متدرجة الرمادي Grayscale Image والصور الملونة Color Iالصور متعددة الأطياف (MultiSpectral Image) I7,3]. وتعد الرؤيسة باستخدام الحاسوب أحد أفرع علم الذكاء الاصطناعي الذي يهدف بشكل عام إلى محاكاة

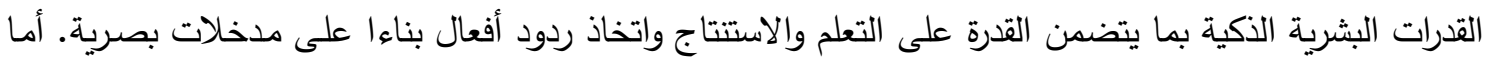
مجال تحليل الصور فيعد مجالا متوسطا بين الرؤية بالحاسوب ومعالجة الصور • ويصعب إلى حد ما إيجاد حدود فاصلة بين هذه المواضيع الثلاثة (معالجة الصور ، وتحليلها والرؤية بالحاسوب) ـ إلا انه يمكن تقسيم العمليات التي يستخدم فيها الحاسوب في هذا المجال إلى ثلاث مستويات [4]: 1- عمليات ذات مستوي منخفض والتي تتضمن إزالة التشوه وتحسين التباين وزيادة حدة الصورة[5] . ويمكن وصف هذه العمليات بأنها تلك العمليات التي يكون إدخالاتها صورة وإخراجاتها صورة. 
2- عمليات ذات مستوي متوسط والتي تتضمن تقسيم الصورة إلى مناطق أو عناصر ثم وصف هذه العناصر

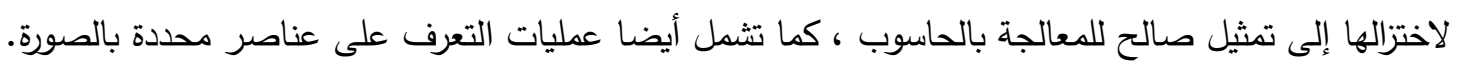
3- عمليات ذات مستوي عال وهذه تتضمن عملية فهم أو إدراك لمجموعة من العناصر التي تم التعرف علئيها. وفي قمة عمليات هذا المستوي تأتي عمليات التعلم واكتساب المعرفة المرتبطة بالرؤية بالحاسوب.

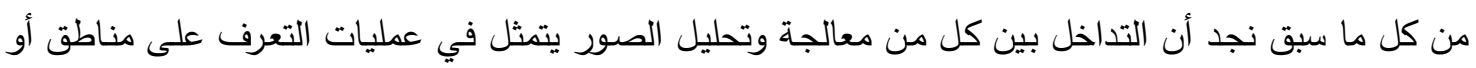
عناصر معينة تتنمي للصورة. ويتم عرض نتائج معالجة البيانات في الحاسوب بطريقة يفهمها المستخدم إما عن فئن

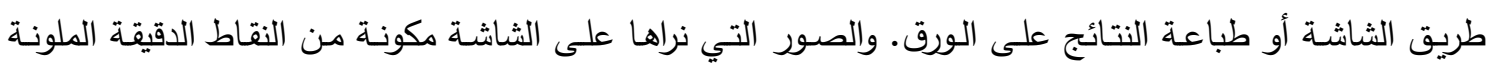

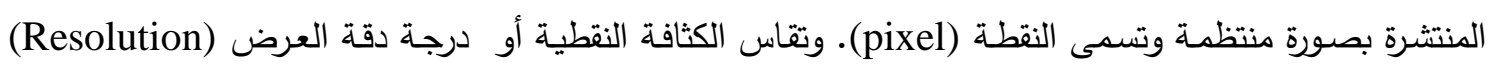

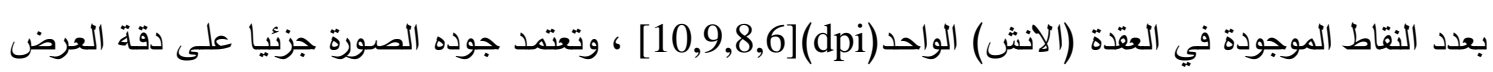
أي كميه التفاصيل التي تستطيع الكاميرا إيجادها وأيضا تعتمد جوده الصورة على درجه جوده العدسة وعدد الألوان

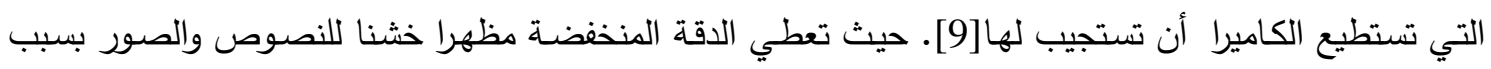

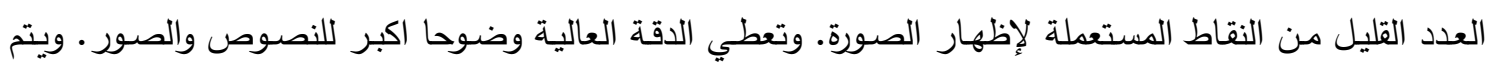
التعبير عن الدقة من حيث عدد النقاط عموديا في عدد النقاط أفقيال[8]. وبما انـه أصبحت عملية معالجـة الصور بالطريقة الرقمية عملية قليلة الكلفة نسبياً وسهلة التتفيذ وذلك للتطور الحاصل في مجال الحاسوب وأجهزة تحويل وتسجيل محتويات الصور دون فقدان في المعلومات التي تحويها هذه

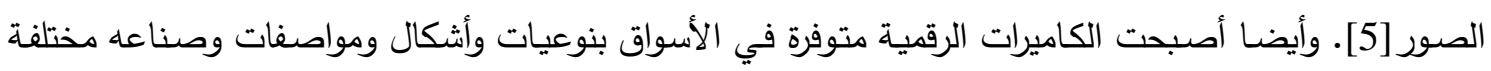

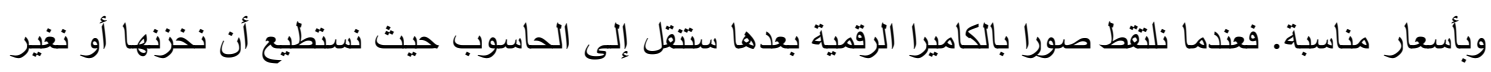

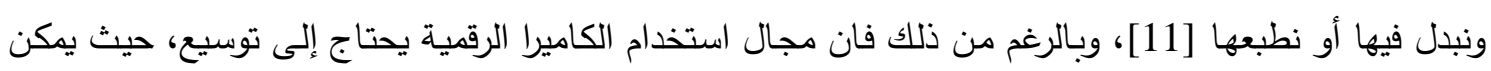

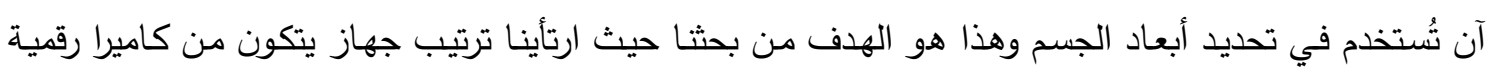
ومصدرين للضوء بحيث تكون الثلاثتة (عدسـة الكاميرا ومصدري الضوه) على خط أفقي واحد وان المسافة بين مصدري الضوء ثابتة وهذه المسافة سيتم اعتمادها لحساب مقياس الرسم للصورة الملتقطة الذي عن طريقه يتت

حساب أبعاد الجسم في الصورة. ليوفر على المستفيدين من هذا الجهاز الجها والوقت والكلفة في أداء مهامهم.

\section{وحدة قياس المسافة داخل شاشة الحاسوب}

إن شاشة الحاسوب مكونة من نقاط مرتبة على شكل شبكة أفقية ورأسية ويمكنك التحكم في دقة العرض العان

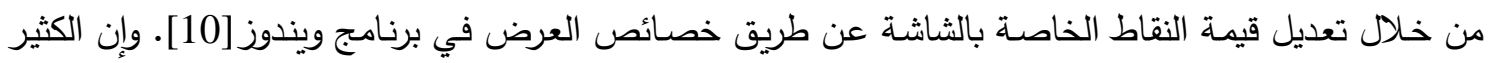

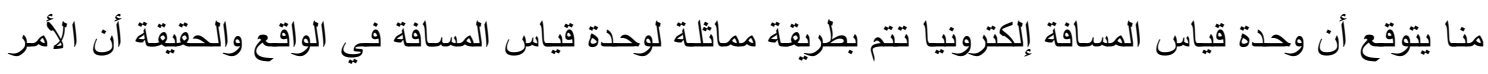

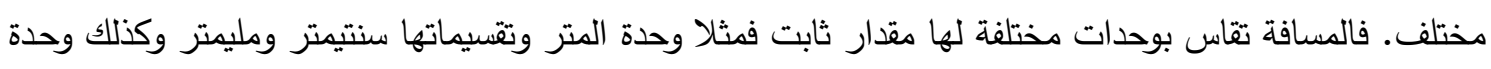

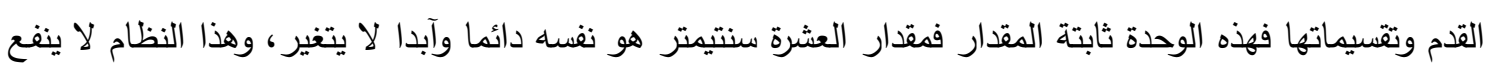
في عالم شاشات الحاسوب. فالمشكلة تتمثل بأنه يوجد شاشات بأحجام مختلفة وبأسعار مختلفة فلو استخدمت وحدات القياس الحقيقة في العالم

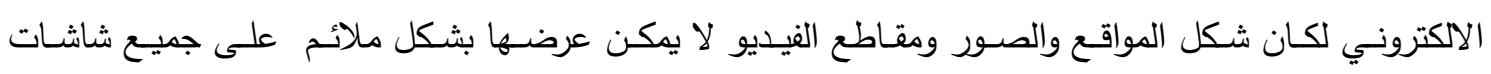


وحلاً لهذه المشكلة تم اختراع وحدة قياس مسافة خاصـة بالثشاشات هي النقطة pixel هذه الوحدة تختلف اختلاف جذري عن الوحدات الحقيقة حيث أن هذه الوحدة ليس لها مقدار ثابت بل يمكن تغيير مقدار هذه الوحدة

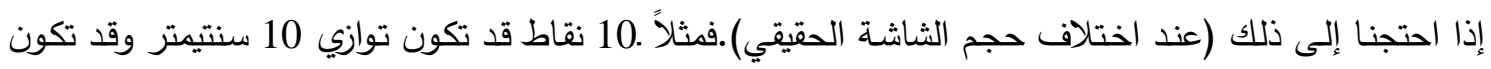
توازي 10 مليمتر وقد توازي 14 سنتيمتر فليس لها مقدار معين بل تختلف باختلاف الثاشة والجهاز .

\section{الكثف عن الحواف باستخدام كاشف كاني ( Canny):}

إن البحث عن خوارزميات وطرائق حديثة لمعالجة هذه الصور لاستخلاص المعلومات الضرورية المهمة

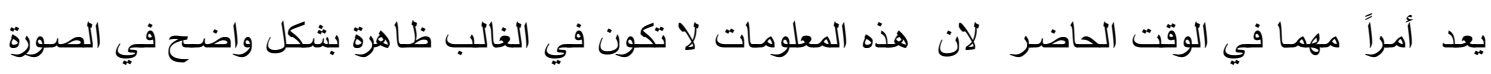
الخام[7]

وقد اقتصرت هذه الخوارزميات والطرائق بشكل رئيسي لاستخلاص المعلومات المكانية والطيفية. فلكل نوع من هذه

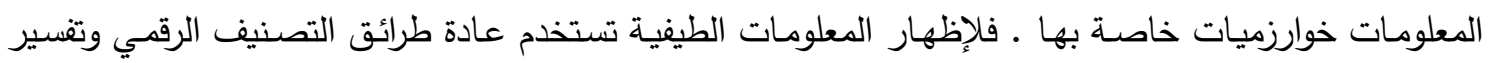
الصور الملونة الكاذبة والمركبة من دمج عدة صور وبحزم مختلفة[13] أما لإظهار المعلومات المكانية نستخدم عادةً خوارزميات تعتمد بشكل أساسي على المرشحات الرقمية.

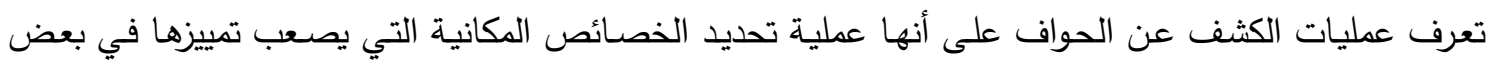

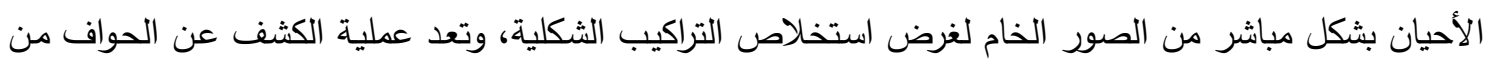
الخطوات الأساسية في فهم وتحليل الصورة، وتثمل عملية الكثف عن الحواف في الغالب تحديد وعزل الحواف من الصورة الرقية باستخدام خوارزميات وطرائق معالجة الصورة الرقمية[7]ت. يعد كاشف كاني للحواف من الخوارزميات الفعالة للكثف عن الحواف، لأنه يعتمد ثلاثة معايير في تقدير كفاءة الخوارزمية، المعيار الأول هو تحقيق اقل نسبة للخطأ في عدد الحواف التي يمكن اكتشافها وهذا يتجلى في عدم التهات تجاهل الحواف الحقيقية بقدر الإمكان وعدم احتساب الحافات الكاذبة بقدر الإمكان. والمعيار الثاني الذي التئي التمدته خوارزمية كاني هو الدقة في تحديد الحافة وهذا يعني تحقيق اقل مسافة ممكنة بين موقع الحافة المحددة وموقعها الإنان الحقيقي في الصورة. أما المعيار الثالث فهو جعل الخوارزمية ذات استجابة واحدة للحافة الواحدة إذ أن هذا المعيار

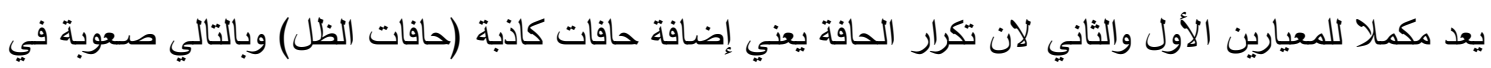
تحديد الموقع الدقيق للحافـة[14]. ولأنها يظهر الحواف الضـعيفة المرتبطـة بالحواف القويـة، فقد تم استخدام هذا الكاشف في البحث للكثف عن الحواف مع الحد الأعلى للعتبة وهو 0.6 حيث اظهر نتائج واضحة.

\section{الجهاز المستخدم في التصوير}

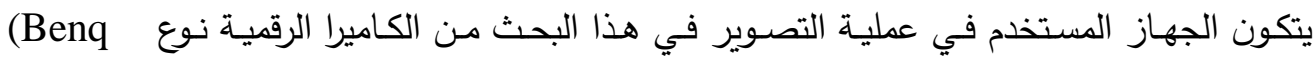

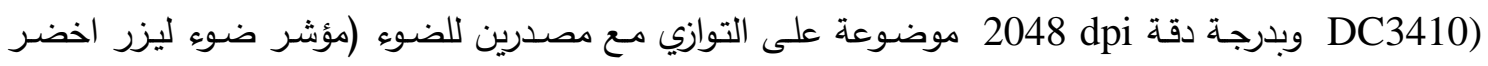
اللون) ومثبتة بإطار من الخشب بحيث تكون عدسة الكاميرا ومصدري الضوه على خط أفقي واحد والمسافة بين

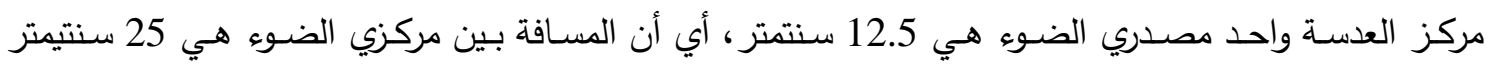

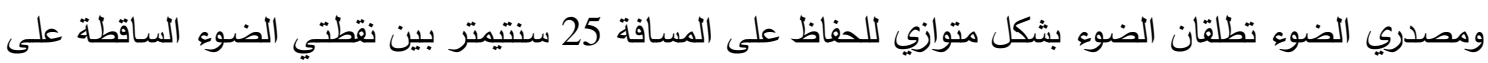
الجسم الذي ستلتقط له الصورة, انظر الثكل(1). 


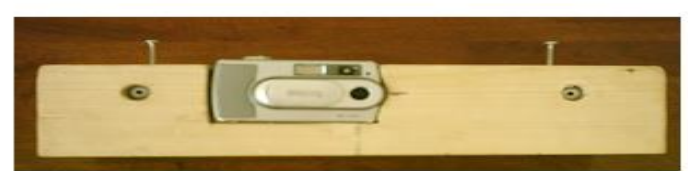

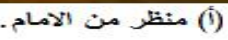

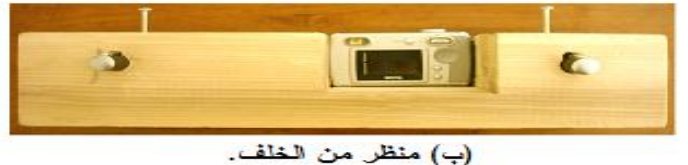

(ب) منظر من النثلف.

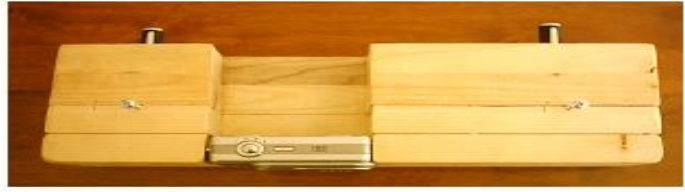

(ج) منظر مث الاعلى

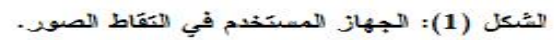

محددات التقاط الصورة

هنالك بعض المحددات يجب مراعاتها لالتقاط صورة بالجهاز المحور لتعطي صورة واضحة بحيث تُمَيز

بشكل دقيق.

1- إذا كان التصوير خارج البناية فيجب أن لا تكون أشعة الثمس مسلطة على الواجهة كليا أو جزئيا، وذلك لكي لايؤثر على وضوح لون الضوء المسلط على الجسم. 2- إذا كان التصـوير داخل البناية فيفضل عدم استخدام الوامض (الفلاش) الخـاص بالكاميرا ولنفس السبب في النقطة السابقة.

3- يكون البعد بين الكاميرا والجسم المراد تصويره مناسب بحيث تظهر النقاط الضوئية بشكل واضح.

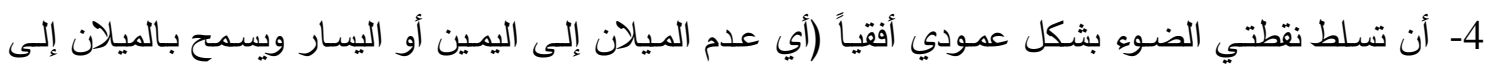
الأعلى أو الأسفل) قدر الإمكان على الجسم.

\section{خطوات إيجاد مركزي نقطتي الضوء المسلطة على الجسم}

إن نقطة الضـوء المسلطة على الجسم في الصـورة الملتقطـة ستتحول إلى دائرة في الصسورة الثنائية بعد استخدام كاشف كاني لاستخلاص الحواف، ولإيجاد مركزي نقطتي الضوء (الدائرتين) المسلطة على الجسم تم استخدام خوارزمية البحث النقطي لاكتثاف الدائرة في الصور الثنائية. ولتنفيذ الخوارزمية يجب أن تكون المدخلات

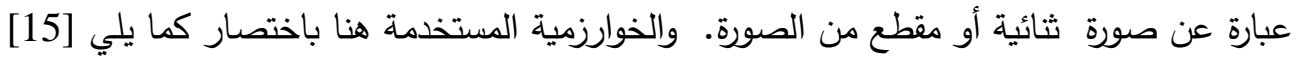
1- تبدأ العملية بالبحث عن نقطة مضيئة في جزء الصورة المقتطع وبشكل عمودي. وبما أن النقطة التي نبحث عنها تقع على محيط الدائرة أو شبه الدائرة، هذا يعني أننا سنجد النقطة على قمـة الدائرة ثم نحتفظ بإحداثياتها (x1,y1)

2- نجد إحداثيات المركز على فرض إن قطعة المستقيم بين النقطتين (x1,y1) و) (x2,y2) تمر بالمركز (تمثل 
3- نحذف الدائرة التي وجدنا مركزها من الصورة المقتطعة وذلك للتقليل من الوقت للازم في عملية البحث لإيجاد

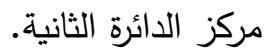
4- تعاد الخطوة (3-1) مرة أخرى لإيجاد مركز الدائرة الثانية(مركز نقطة الضوء الثانية).

\section{خطوات حساب مقياس الرسم للجسم في الصورة}

لحساب مقياس الرسم يجب أن تكون قيمـة المسافة بين نقطتي الضـوء المسلطة على الجسم معلومـة

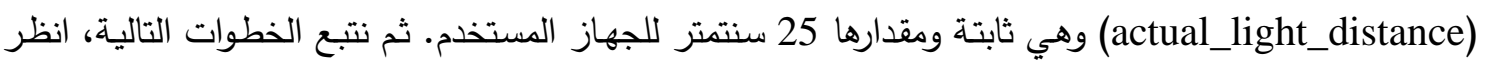
الشكل(2):

1- تحويل الصورة إلى صورة ذات التدرج اللوني الأخضر (green plane)، وذلك لان الضوء المستخدم ذو لون اخضر وهذا المستوي أعطى نتائج واضحة في تمييز دائرتي نقطتي الضوه في الصورة الثنائية. 2- قطع جزء الصورة الذي يحتوي نقطتي الضوء، وبما أن عدسة الكاميرا تقع وسط مصدري الضوء وعلى التوازي لذا سيكون موقع نقطتي الضوء في التلث الوسطي من الصورة تقريبا ولجميع الصور في الوضع الصحيح. 3- تحويل الصورة الناتجة إلى الصورة الثنائية باستخدام كاشف كاني للحواف وأن القيمة العليا للعتبة (0.6). 4- عمل تتحيف (thinning) للصورة الناتجة وذلك للتخلص من النقاط الزائدة. 5- نجد مركزي نقطتي الضوء في مقطع الصورة الناتجة (وذلك للحصول على أدق مقياس الرسم ) كما بينا في من الفقرة السابقة، ثم نجد المسافة (Image _Light_distance) بين مركزي نقطتي الضوء في الصورة وحسب Image_Light_distance $=\sqrt{(\mathrm{x} 1-\mathrm{x} 2)^{2}+(\mathrm{y} 1-\mathrm{y} 2)^{2}}$

6- حساب قيمة مقياس الرسم (Scale) كما في المعادلة (2)....... Scale = Image _Light_distance /actual_light_distance 


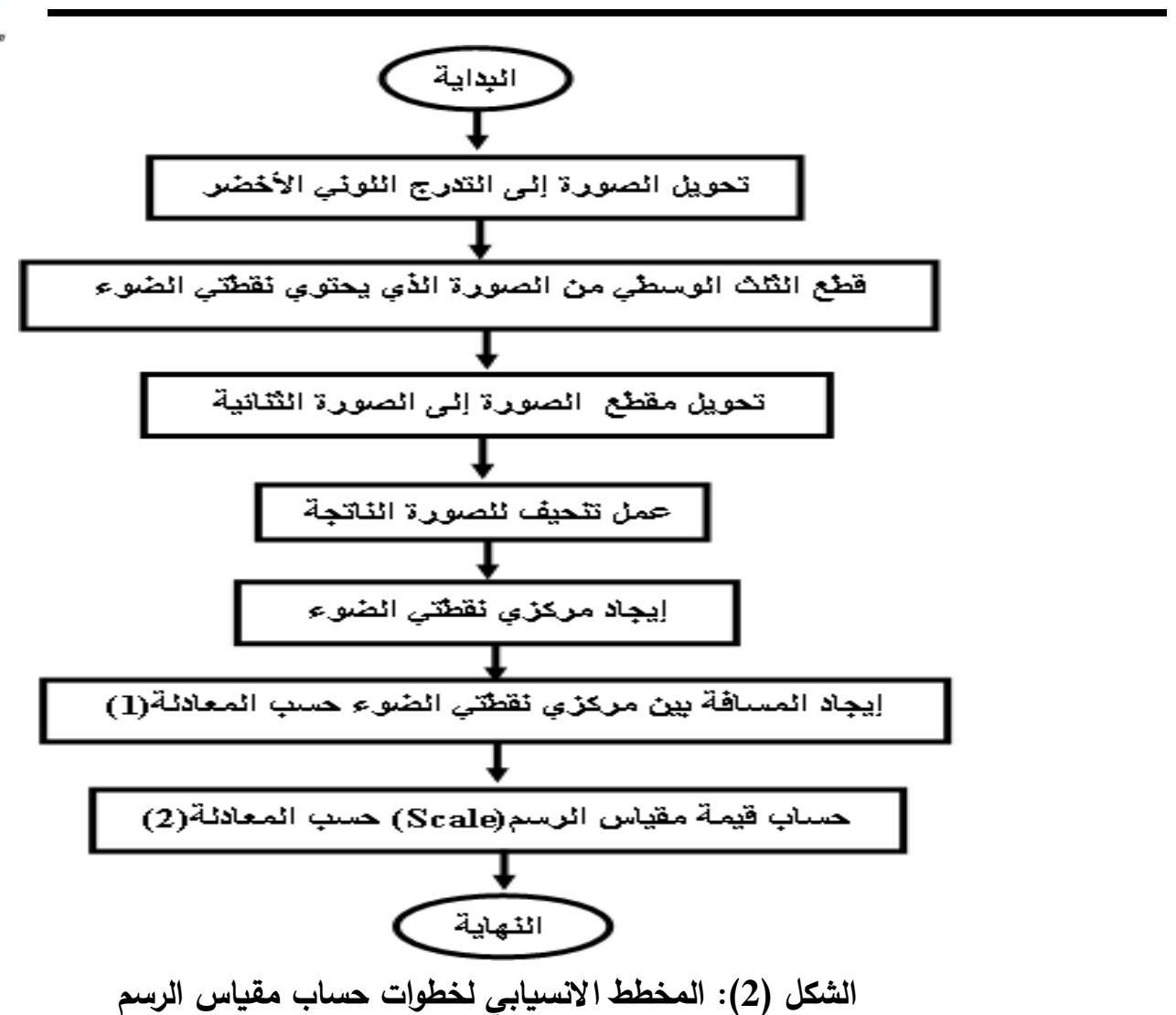

مراحل عمل الخوارزمية المقترحة

يتكون العمل من خوارزمية تعمل على الصور الملونة الملتقطة بواسطة الكاميرا الرقمية للجهاز المستخدم الذي تم ترتيبه كإدخال، وأما الإخراج فهو قيم أبعاد جسم معين في الصورة المدخلة. وخطوات الخوارزمية مبينة بالمخطط الانسيابي في الثكل(3) وكما يلي: 1- التقاط صورة بواسطة الكاميرا الرقمية للجهاز المستخدم الذي تم ترتيبه بحيث تكون نقطتي الضوء مسلطة على وسط الجسم قدر الإمكان وبشكل عمودي على الجسم.

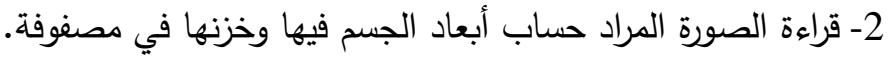
3- حساب قيمة مقياس الرسم( Scale) المستخدم في هذه الصورة كما في الفقرة الصابقة. 4- تحديد نقطة بداية ونقطة نهاية للمسافة المراد قياسها على الجسم في الصورة وذلك بتأشير النقاط بواسطة الفأرة

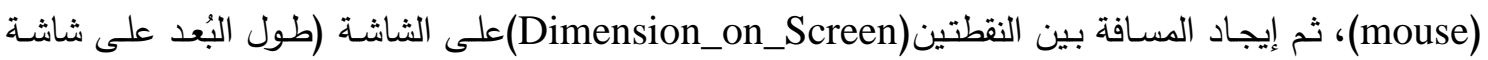

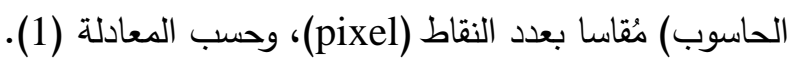
5- حسـاب المسافة الحقيقية وهي تسـاوي حاصل قسمة طول المسافة على شاشـة الحاسوب مقسوما على قيمـة مقياس الرسم لهذه الصورة كما في المعادلة (3). ويكون الناتج بوحدة السنتيمتر . Actual_dimension=Dimension_on_Screen / Scale

6- طباعة قيمة المسافة (أو الأبعاد) الحقيقية على الثاشة في الموقع المناسب. 7- كرر الخطوة 6-4 في حالة قياس مسافة أخرى على الجسم في الصورة. 8 - النهاية - 20 - n 


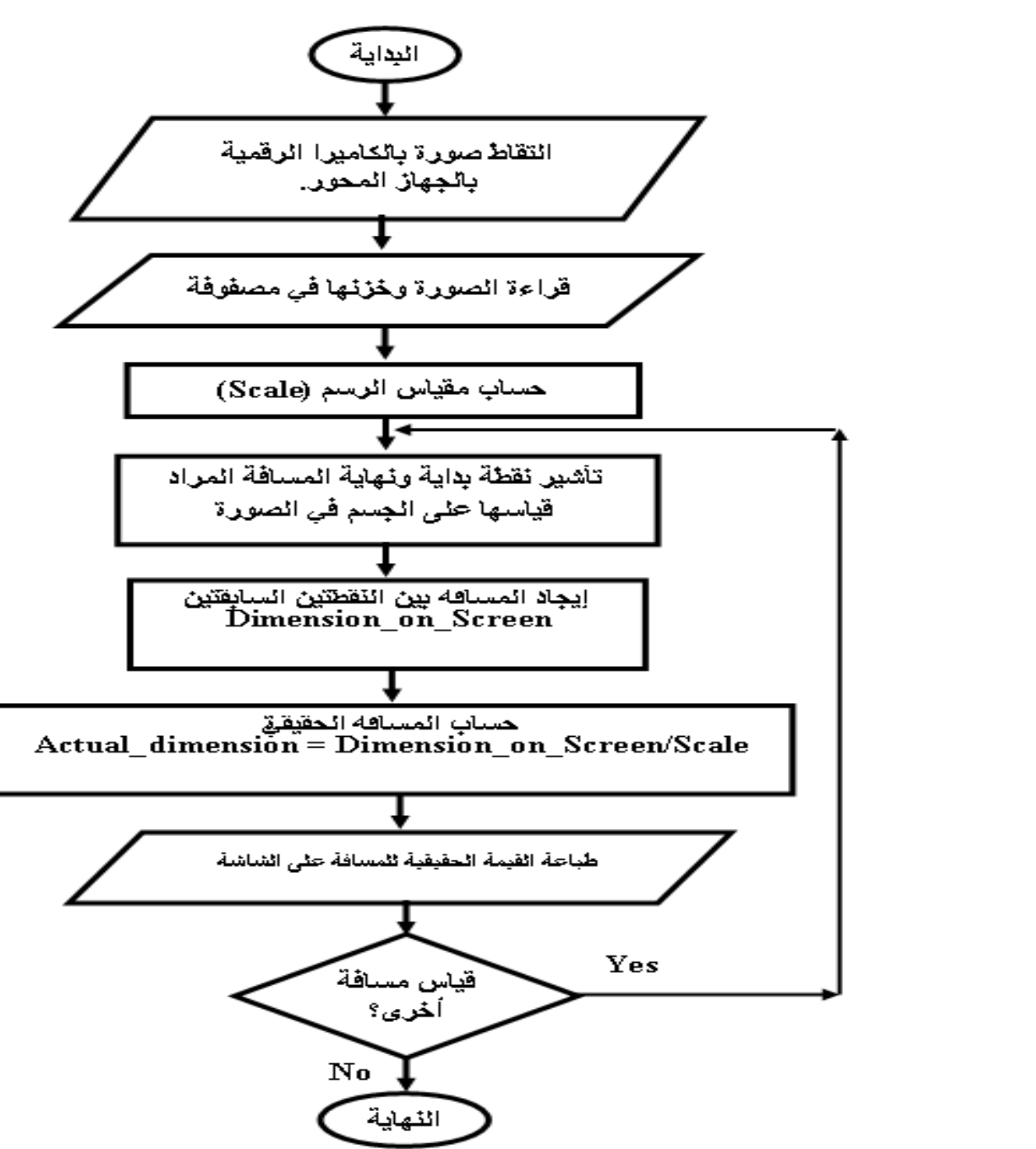

الثكل (3): المخطط الآسيابي لمراحل عمل الخوارزمية المقترحة 
اختبار كفاءة الخوارزمية المقترحة:

يمكن قياس مدىى كفـاءة الخوارزميـة مـن خـلال حسـاب النسبة المئويـة لدقة المسـافات التي وجدت إلى

المسافات على الواقع وحسب القانون:

$$
A c c=\frac{I D}{A D} * 100
$$

$$
\begin{aligned}
& \text { إذ إن : Acc هو النسبة المئوية للدقة. } \\
& \text { هو المسافة التي تم إيجادها من الصورة. AD } \\
& \text { AD }
\end{aligned}
$$

تم تطبيق الخوارزمية على مجموعة من الصور المختلفة ذات الامتداد (jpg) وعددها حوالي 60 صورة تحتوي

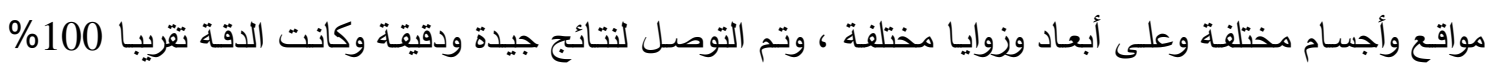
لأغلب الصور حيث أن بعض الاختلاف في تحديد الأبعاد بشكل دقيق كانت نتيجة عدم دقة المستخدم في تحديد

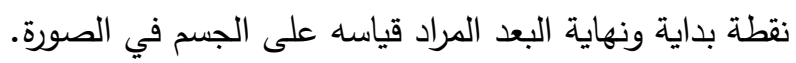

\section{أمثلة تطبيقية}

$$
\text { فيما يلي بعض الصور الملتقطة ونتائجها: }
$$

المثال 1: (1)

في هذا المثال التقطت صورة لجزء من واجهة دار لقياس ارتفاع سياجه والمبينة بالثكل(4) الصورة (أ)، وكانت الكاميرا على بعد 10 أمتار تقريبا، لاحظ أن مصدري الضوه سلطا بشكل عمودي تقريبا على السياج المطلوب حساب ارتفاعه.

الصورة (ب) تمثل الصورة الناتجة ذات التدرج اللوني الأخضر ، والصورة (ج) تبين الجزء المقتطع من الصسورة السابقة والتي تحتوي نقطتي الضوه، والصورة (د)هي الصورة الناتجة من تحويل الصورة (ج) إلى الصورة الصنئ الثنائية باستخدام كاشف كاني، أما الصورة (هـ) فتبين الصورة بعد تطبيق خوارزمية البحث النقطي لتمييز الدائرة حيث تم

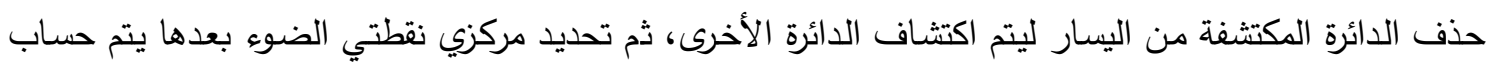
مقياس الرسم. والثكل(5): في الصورة (أ) نلاحظ ظهور المؤشر مبينا الاحداثي السيني والصادي ليستطيع المستخدم تحديد نقطة بداية المسافة المراد قياسها على الصورة. والصورة (ب) تبين موقع نقطة النهاية للمسافة المراد قياسها على الصورة.

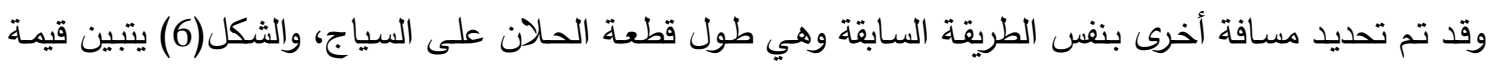
البعدين مطبوعة على الصورة وهي فعلا تساوي البعدين في الحقيقة. 


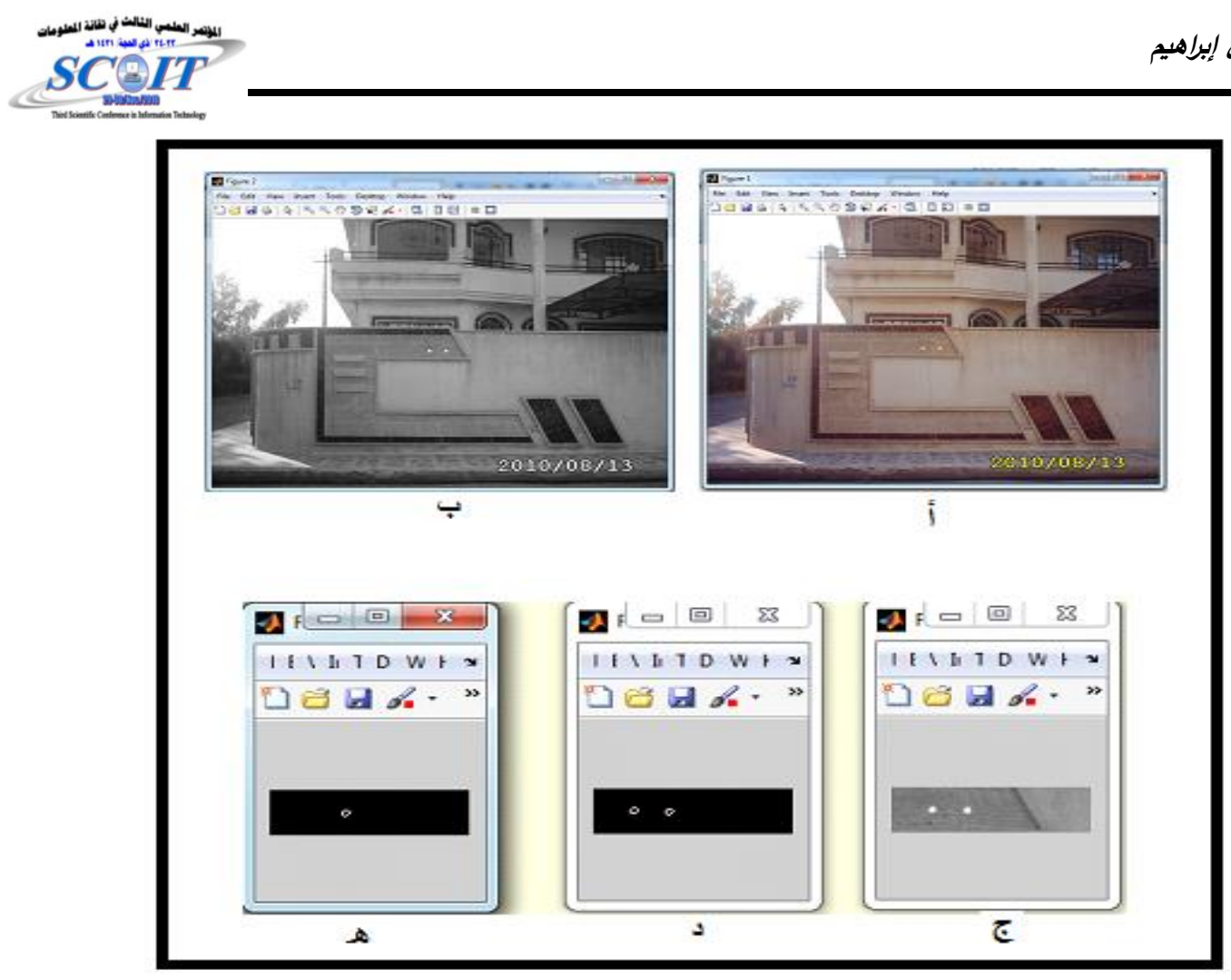

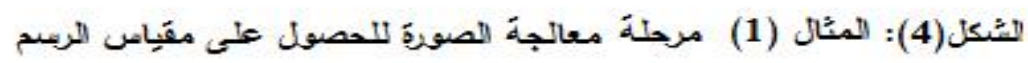

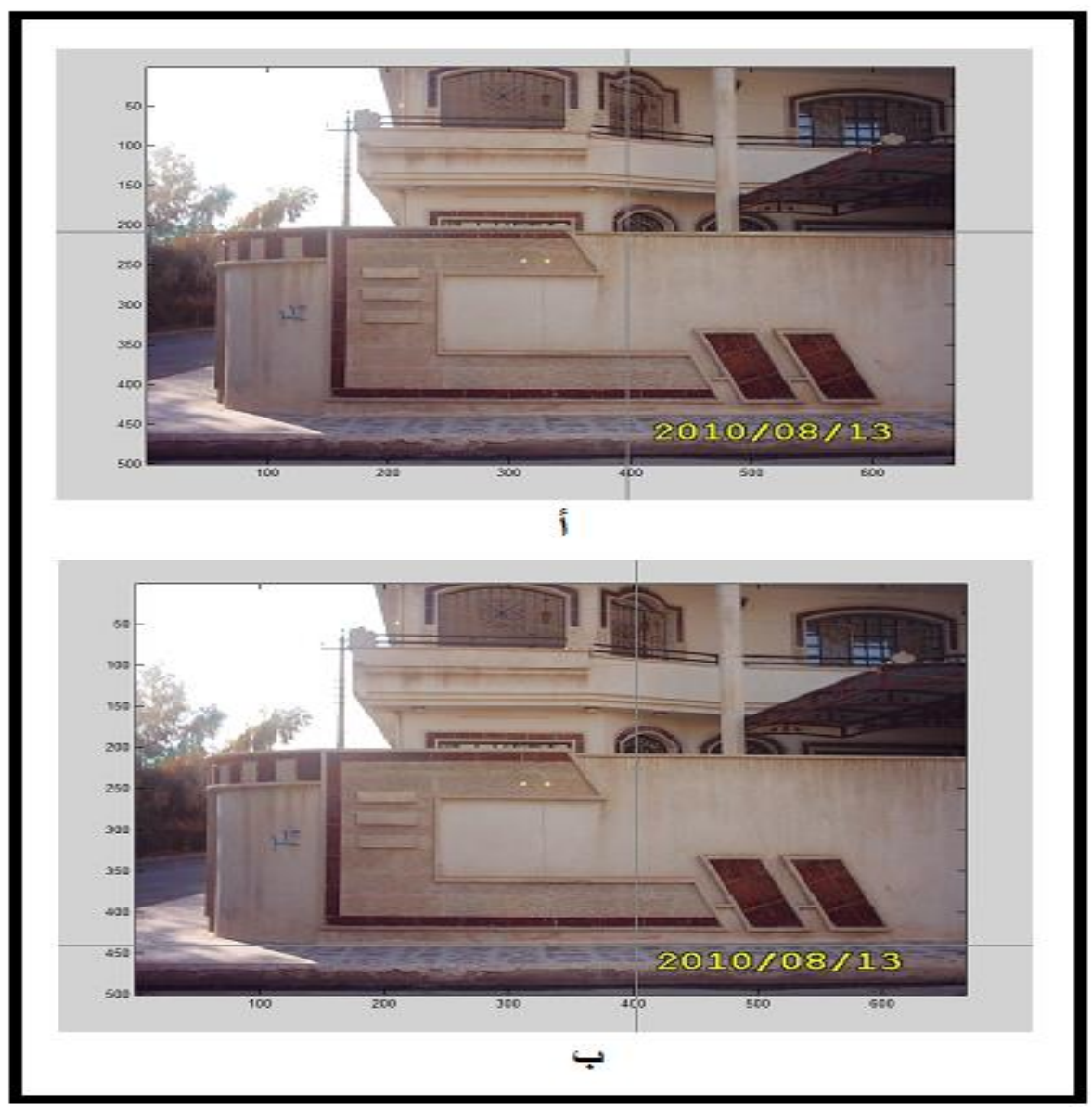

الششكل(5): المثّال (1) تأثشير الابعاد على الصوية. 


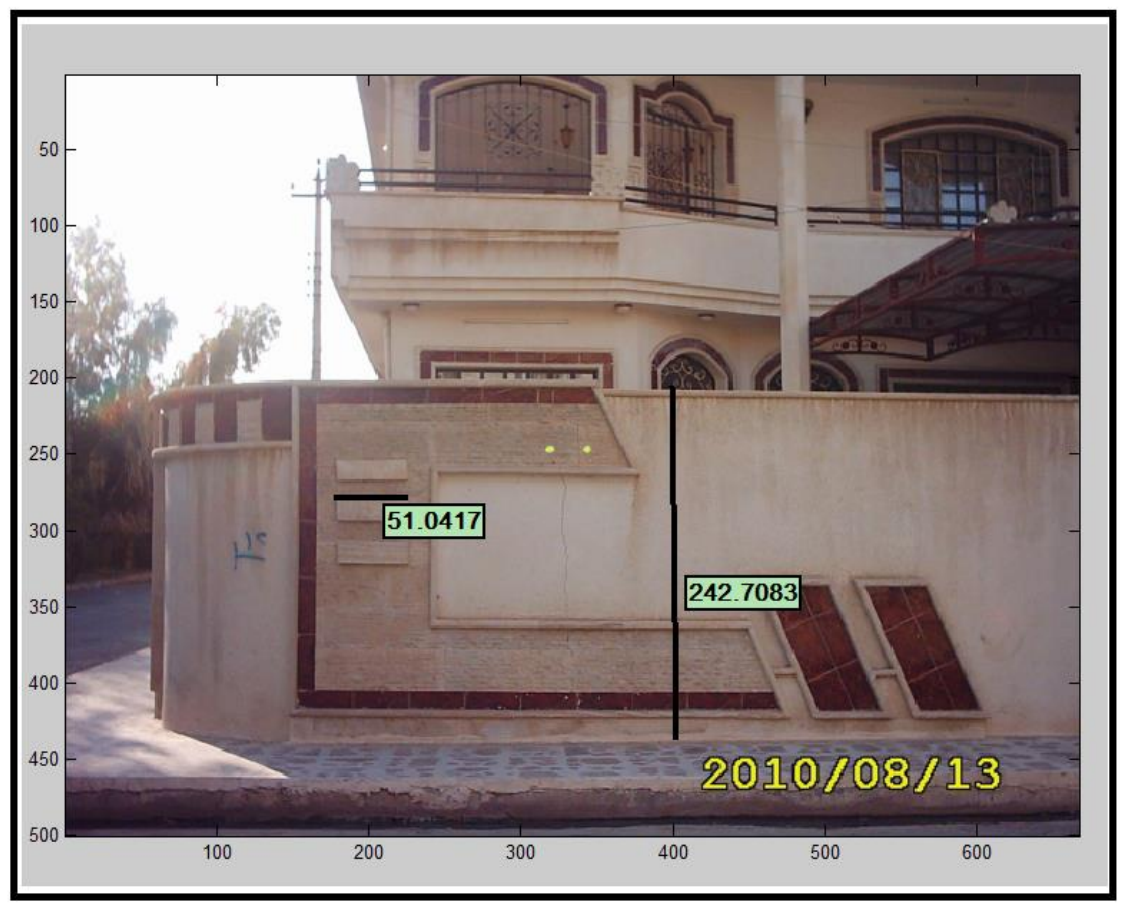

الثكل(6): طباعة الإبعاد على الصورة.

المثال 2: - م:

تم التقاط صورة لمركبة حمل لقياس ارتفاعها، وقياس طول الحمل الخارج عنها انظر الصورة (أ) من

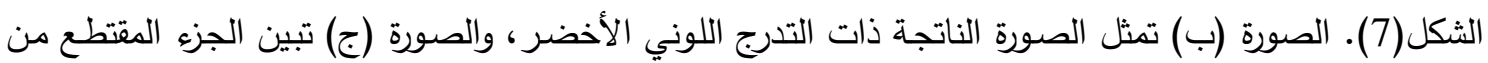

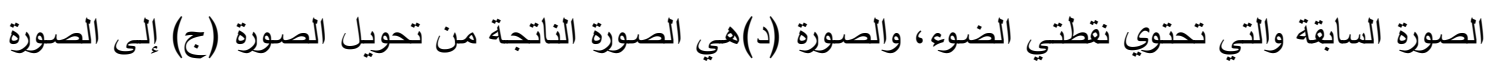
الثنائية باستخدام كاشف كاني، أما الصورة (هـ) فتبين الصورة بعد تطبيق خوارزمية البحث النقطي لتمييز الدائرة

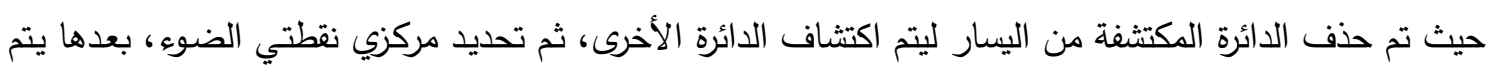
حساب مقياس الرسم. الثكل (8): الصورة (أ) نلاحظ ظهور المؤشر مبينا الاحداثي السيني والصـادي ليستطيع المستخدم تحديد نقطسة بداية الحمل الخارج عن المركبة. والصورة (ب) تبين موقع نقطة نهاية الحمل الخارج عن المركبة المراد قياسه في

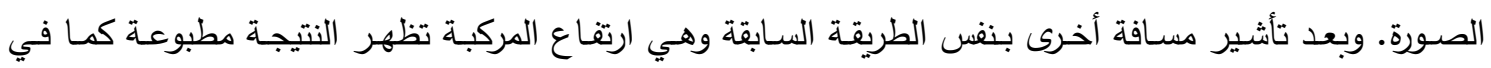
الشكل(9). 

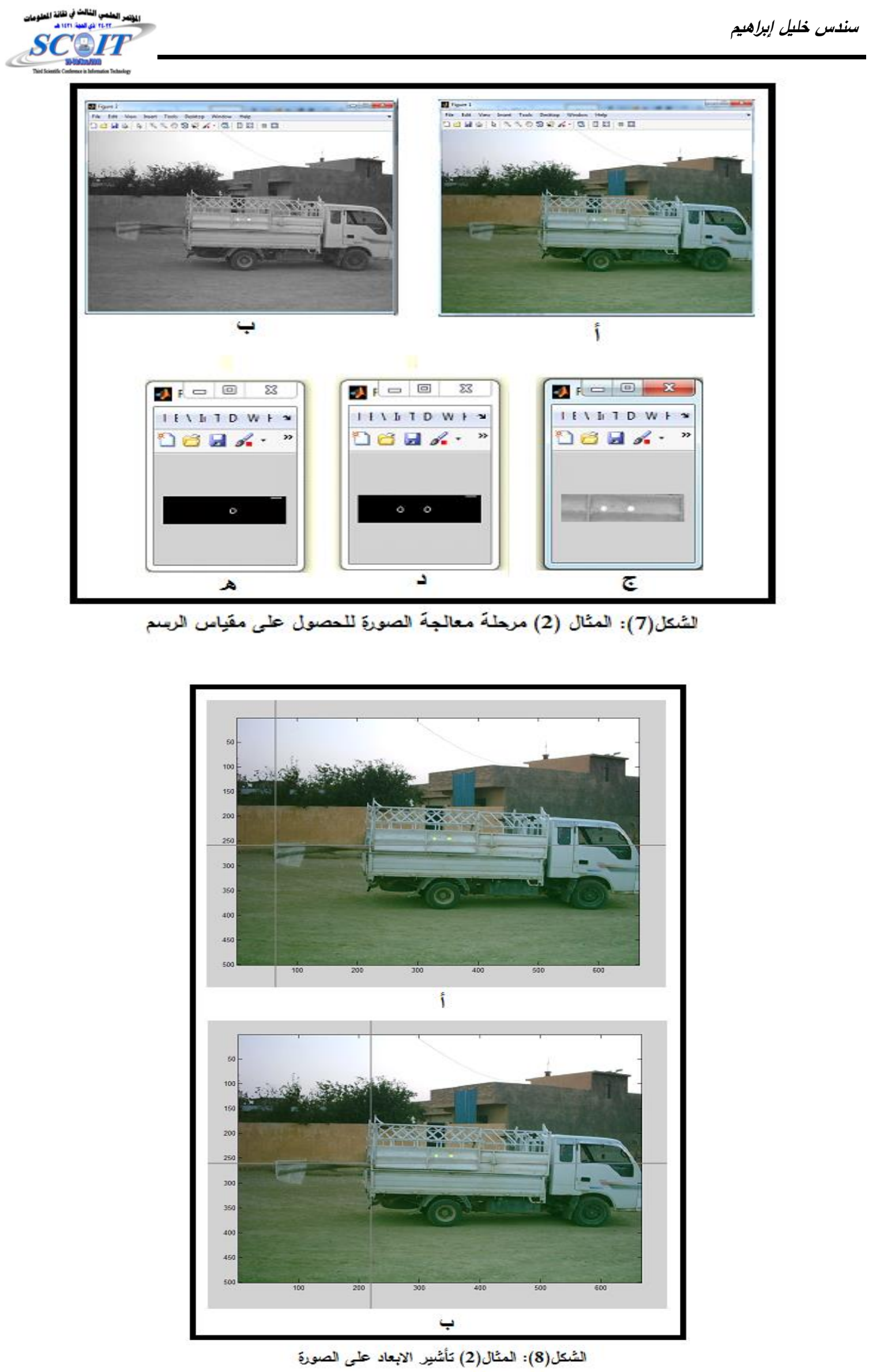


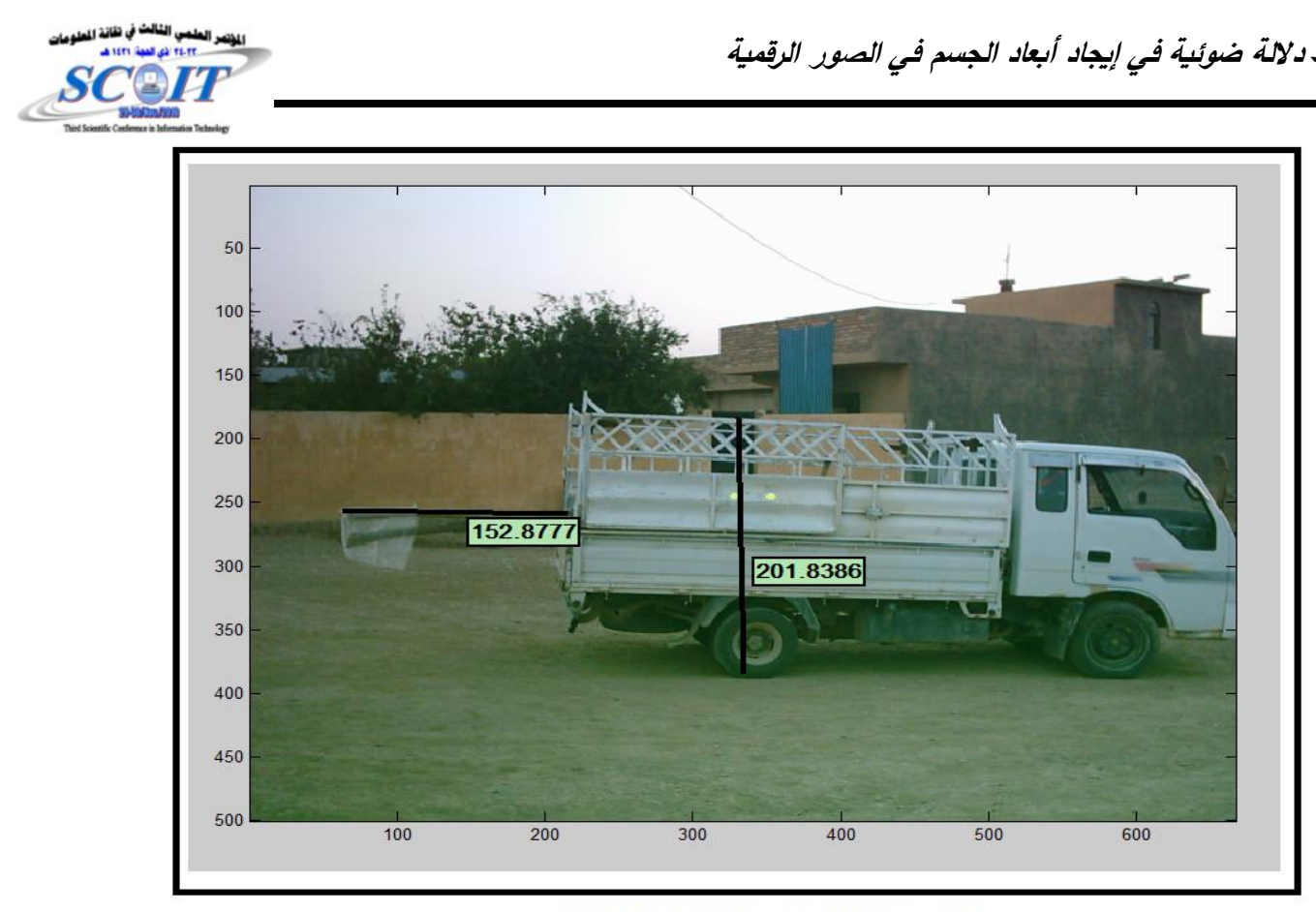

الثنكل(9): المثال (2) طباعة الابعاد على الثناثة.

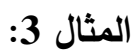

الثكل (10-أ) يبين صورة لطفل يراد قياس طوله، وهو يحمل مسطرة القياس لنبين مدى صحة ودقة النتائج، حيث

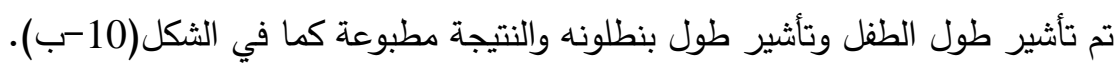

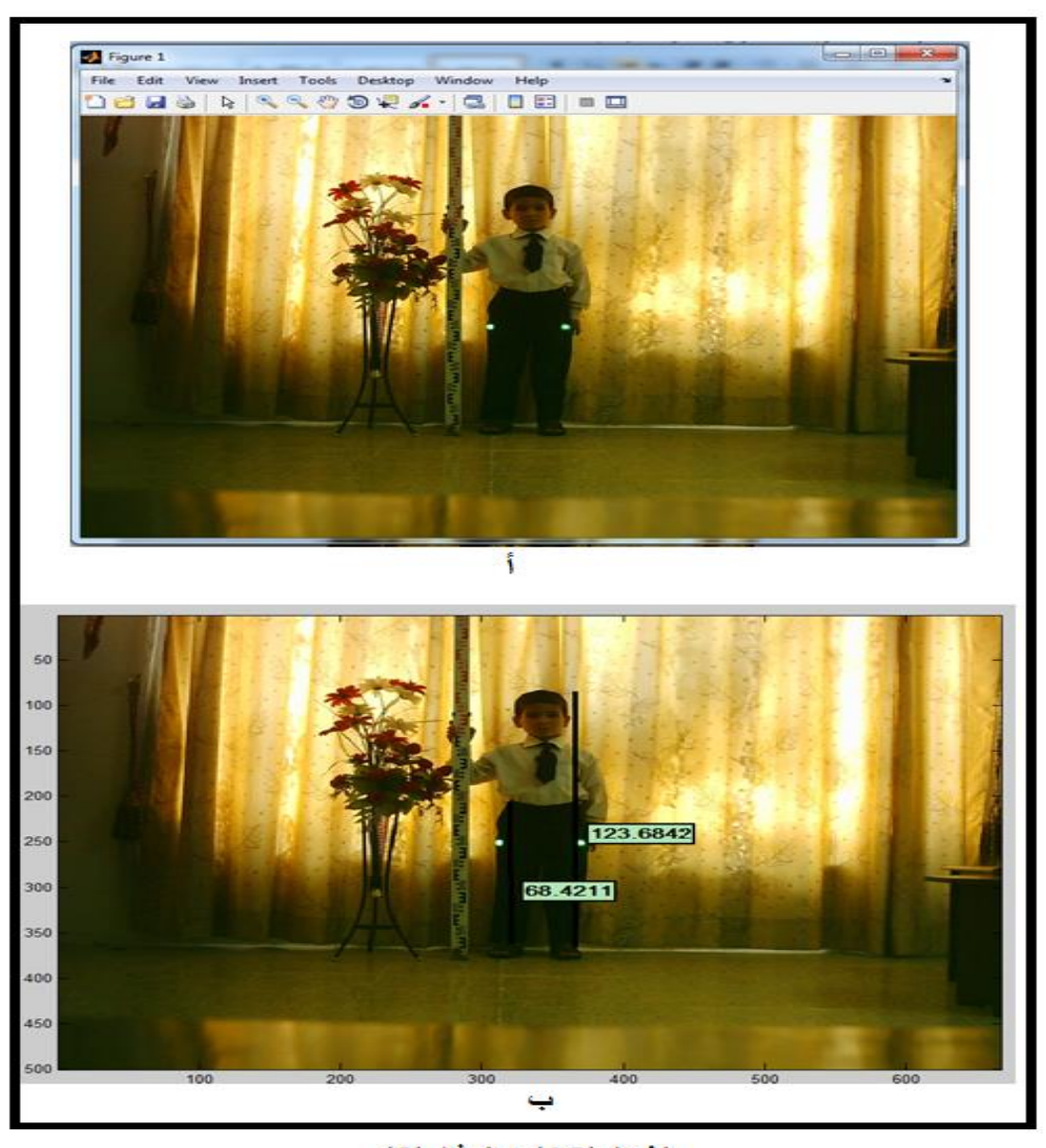

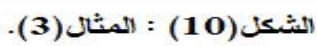


الصورة في الثكل(11-أ) التقطت على بعد 10 أمتار تقريبا من البنايـة، وبعد تأشير بدايـة ونهايـة

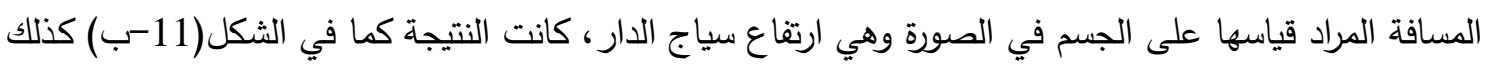

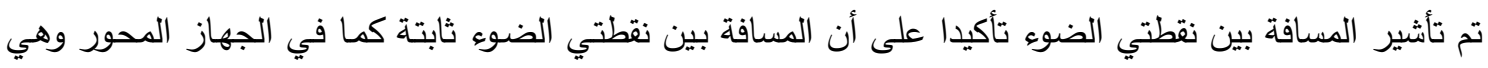
25 سنتيمتر وقد ظهر ذلك في الصورة الناتجة.

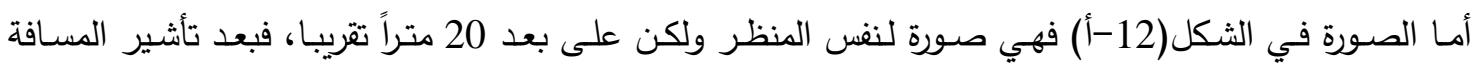

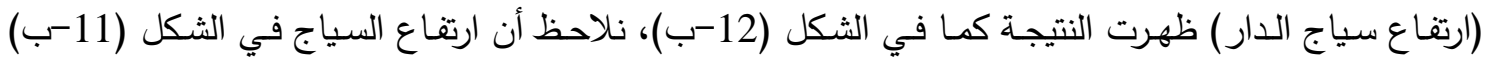
يختلف عن ارتفاع السياج في الثكل (12-ب) التابع لنفس الدار بمقدار 2 سنتيمتر ، والسبب في ذلك هو عدم دقة المستخدم في تأثير بداية ونهاية المسافة مما يؤدي إلى ظهور هذا الاختلاف، عليه فان المستخدم إذا توخى الدقة

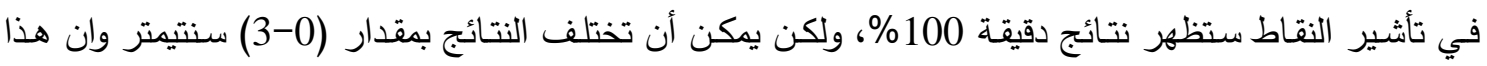
الاختلاف مقبول جدا، ففي مجال المرور بالنسبة لارتفاع المركبة فان إضافة (2-3) سنتيمتر إلى الارتفاع لا يؤثر

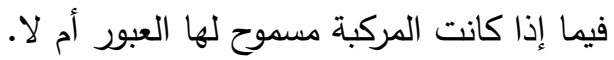
كذلك بالنسبة لواجهات البنايات، فالأبعاد تقاس بالأمتار ، فإضافة (2-3) سنتيمتر كحد أقصى لايؤثر في عملية

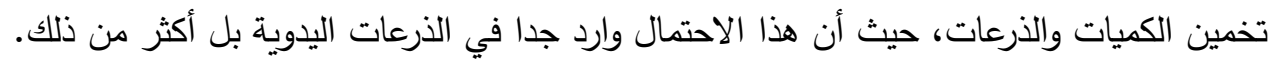

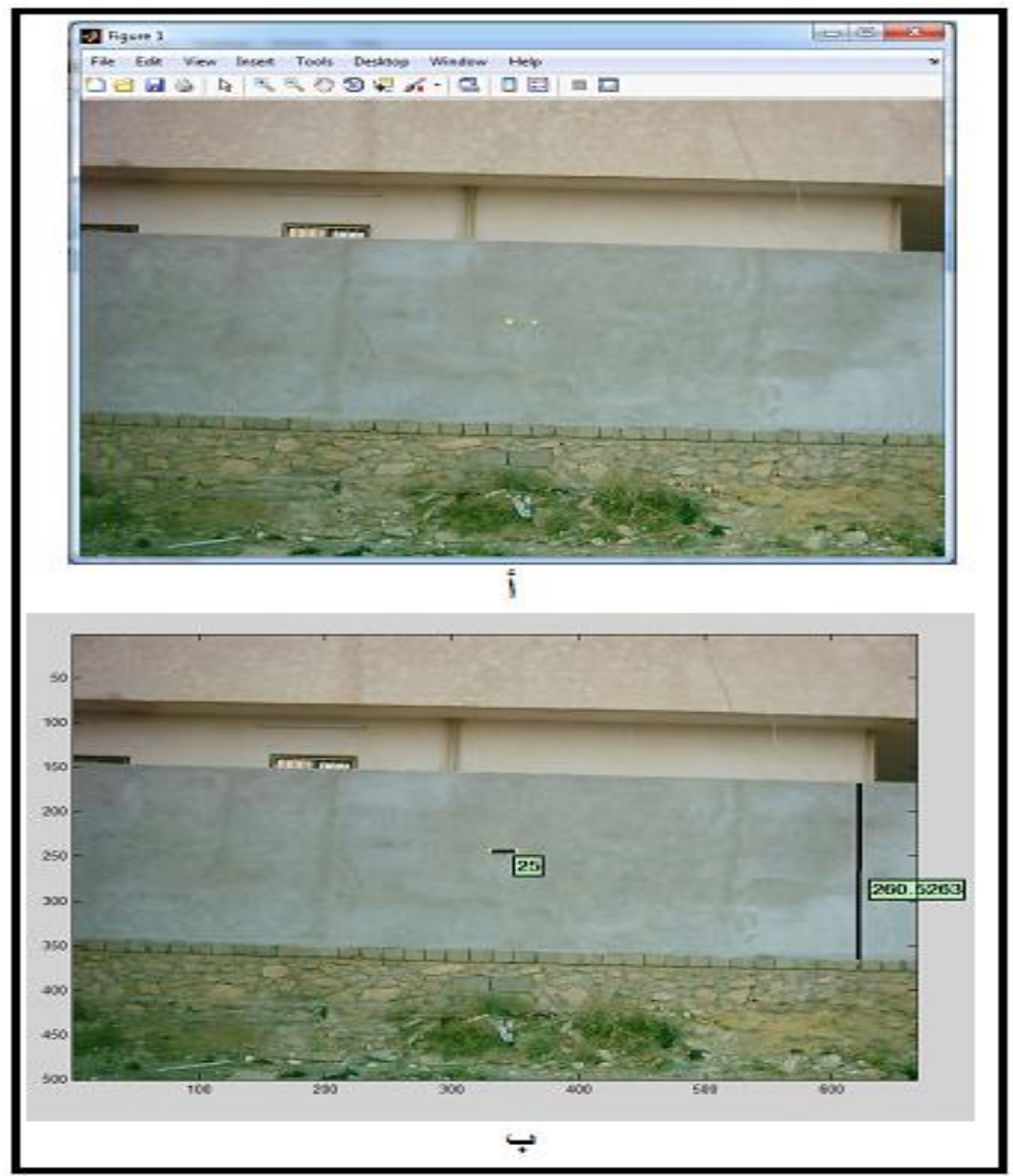

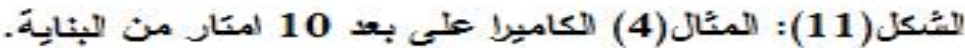




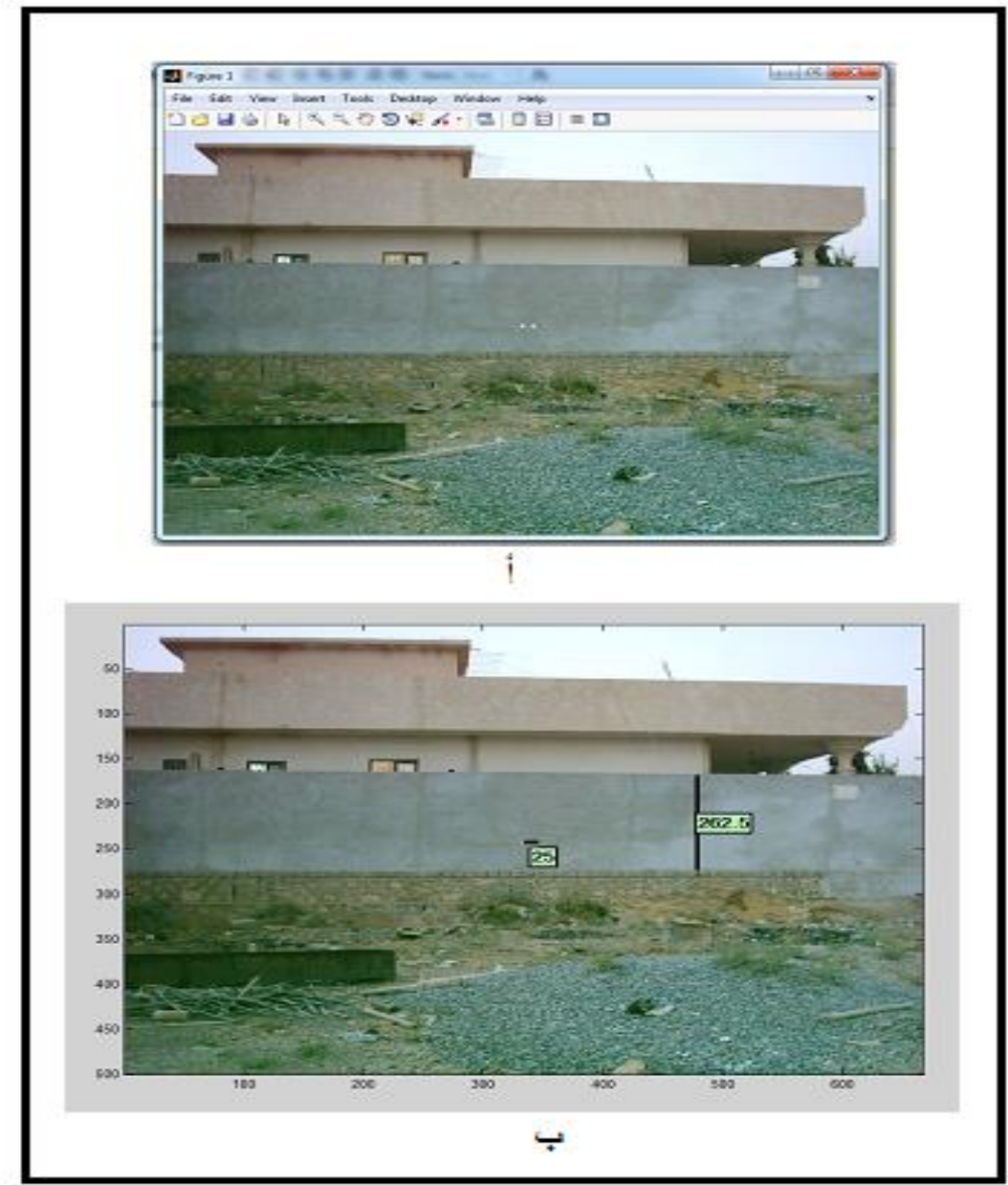

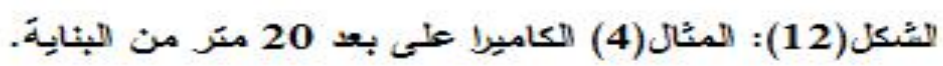

الاستنتاجات

1- بمـا أن وحدة قياس المسافة على شاشة الحاسوب هي النقطة، لذا فان دقة المستخدم في تحديد نقطة على الثاشة يؤثر على قياس أبعاد الجسم الحقيقية الناتجة.

2- إن بعد الكاميرا عن الجسم المراد التقاط الصورة له لقياس أبعاده، يؤثر على حجم الجسم في الصورة، فكلما

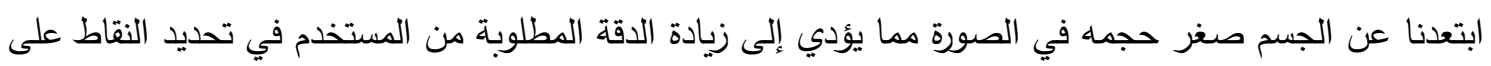
الثاشة. والعكس صحيح، فكلما قل البعد عن الجسم سهل على المستخدم تحديد النقاط. 3- بما أن النقطة هي العنصر الأساسي للصور الرقمية المحفوظة على جهاز الحاسوب سواء حصلت عليها من

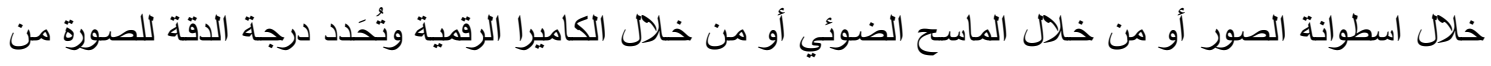
خلال عدد النقاط التي سيتم طباعتها في العقدة (الإنش) [16] ـ عليه فان التغيير في درجة دقة الثاشـة مـع بقاء درجة دقة الكاميرا نفسها والصورة نفسها لايؤثر على قيمة مقياس الرسم. 4- إن الأجزاء المضافة للجهاز المستخدم متوفرة في الأسواق وبأسعار مناسبة وعملية تثبيتها وتركيبها في إطار خثبي أو معدني عملية سهلة وغير مكلفة لذا يستطيع أي شخص أن يقوم بتركيبه والاستفادة منه في مجال عمله. 
5- أثبتت فكرة البحث كفاءة عالية ودقة في إيجاد المسافات المحددة من قبل المستخدم ويمكن الاستفادة منها في: أ. مجال الهندسة المدنية، لتحديد الأبعاد في واجهات البنايات وبالتالي لحساب كميات المواد من الحسلان والسيراميك واللبخ والنثر والصبخ اللازمة، وحساب الذرعات وغيرها.

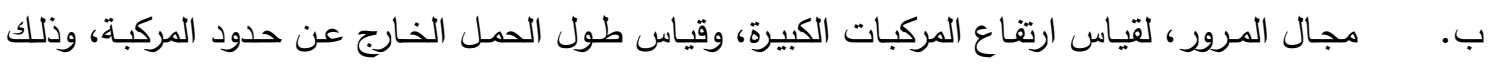

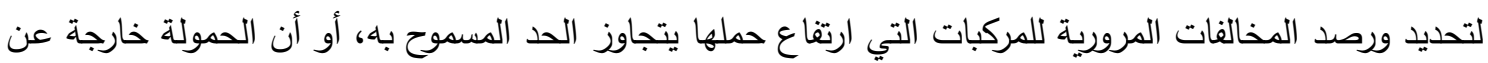
الحدود المسموح بها للمركبة من كل جهة.

ج. مجال دراسة الحيوانات لقياس أطوال الحيوانات الغير الأليفة عن بُعد بالتقاط صورة للحيوان، حيث يتم في

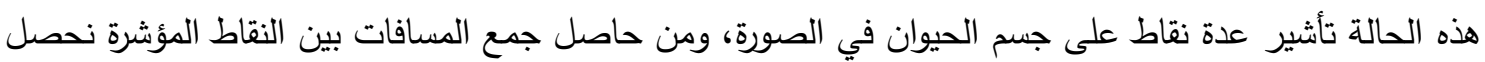
على طول الحيوان، أو طول أي جزء من أجزاء جسمه.

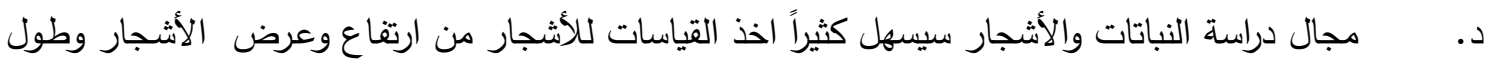
الأغصان والتفرعات وغيرها من القياسات التي يحتار الدارسون في كيفية قياسها بطرق تقليدية مضنية وصعبة. هـ. تحديد قياسات ملابس الثخص من خلال الصورة الملتقطة وإرسالها إلى الخياط لخياطة الملابس دون الحاجة لحضور الثخص المعني أمام الخياط لأخذ القياسات. 


\section{المصادر:}

البشير ، غصون سالم،"استخدام الخوارزمية الجينية في مطابقة الصور"، رسالة ماجستير ،جامعة الموصل،

$$
\text { كلية علوم الحاسوب والرياضيات، قسم علوم الحاسوب، (2003). }
$$

الطحان، نجم عبدالله عبد القادر ، "كثف الوجه وتحديد بالصور الملونة" رسالة ماجستير ،جامعة الموصل،

$$
\text { كلية علوم الحاسوب والرياضيات، قسم علوم الحاسوب، (2004). }
$$

المولى، محمد ناظم داؤد ،"تقطيع صور أورام الدماغ ممثلة بالخوارزميات الجينية"، رسالة ماجستير ،جامعة

$$
\text { الموصل، كلية علوم الحاسوب والرياضيات، قسم علوم الحاسوب، (2007). }
$$

[4]. http://www.eladawy.com/.../introduction\%20to\%20image\%20processing1.doc

[5]. Gonzales R. C. and Wood R. E. : Digital Image Processing, $2^{\text {nd }}$ Eddition, NewYork, pp(585-591), (2002).

[6]. $\quad$ http://www.qataru.com/vb/shwthread.php?t=59338.

الصفار، الحان أنور يونس ، "التمييز الآلي للخطيات وأنظمة التصريف في الصور الفضائية"، جامعة

$$
\text { الموصل، كلية علوم الحاسوب والرياضيات،(2004). }
$$

الزعبي، محمد بلال; حمدان، موسى عبدالله ; الزعبي، خالدة محمد; البطش، هاني محمود،" الحاسوب

$$
\text { والانترنيت"، زمزم للنشر والتوزيع، الطبعة الأولى ، (2009). }
$$

[9]. http://arab-training.com/vb/t3831.html .

[10]. http://www.hazemsakeek.com/.../photoshop/photoshop_2.html.

[11]. Torsten S., "Digital Image Processing using Local Segmentation",School of Computer Science and Software Engineering, Faculty of Information Technology, Monash University, Australia. PhD thesis ,( 2002).

$$
\text { http:// docs.educdz.com/وحدة-قياس-المسافة-داخل-شاشة-الحاسوب }
$$

[13]. Tahir A. A. and AL-Barhawi D., "An Interactive Software for Satellite Image Filtering Using Fourier Domain”, AL-Rafidan Journal, Vol. 13, No. 1,University of Mosul, (2001). Cited by [7].

[14]. Canny J., "A computational Approach to Edge Detection”, IEEE. Transcaction on Patteren Analysis and Machine Intelligence, Vol. 8, No. 6, pp(679-698), (1986). Cited by [7].

[15]. Ebraheem S. Kh.," A Suggested Point Search Algorithm for Circle Detection in Binary Images" ,Al_Rafdan Journal of Computer Sciences and Mathematics, Accepted for Publishing on 16/5/ 2010.

[16]. Filippo S. , "Image Enhancement Techniques: Zooming and Super Resolution", thesis, University Degli Studi Catania, (2003), from Abstract. 